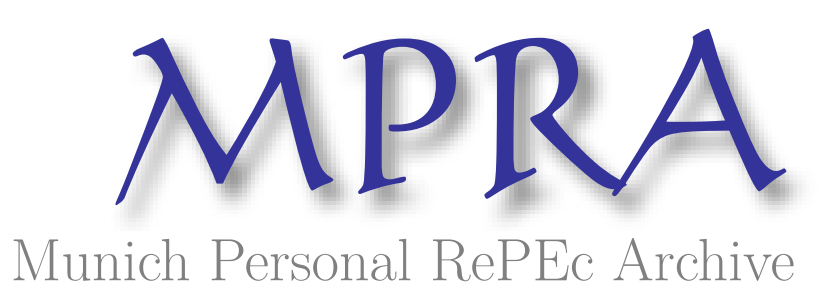

\title{
Local Tax Limits, Student Achievement, and School-Finance Equalization
}

Davis, Matt and Vedder, Andrea and Stone, Joe

U. Oregon, U. Oregon, U. Oregon

January 2015

Online at https://mpra.ub.uni-muenchen.de/63704/

MPRA Paper No. 63704, posted 20 Apr 2015 17:52 UTC 


\title{
Local Tax Limits, Student Achievement, and School-Finance Equalization*
}

\author{
Matthew Davis, Andrea Vedder, and Joe Stone \\ Department of Economics, University of Oregon
}

January 2015

\begin{abstract}
Evidence that local tax and expenditure limits (TELs) for public K-12 schools lower student achievement is widely attributed to the effects of reduced funding, but our results cast doubt on reduced funding as the primary explanation for negative effects of TELs in the context of school-finance equalization (SFE) and instead suggest the importance of predictable funding. Students in districts subject to more severe local tax limits in Oregon score less well on eighthgrade tests in mathematics, but reduced funding is not the reason. Our analysis expands prior work by accounting for the extent to which TELs are actually binding, as well as for both pecuniary and non-pecuniary effects of TELs. Distinguishing pecuniary and non-pecuniary effects allows us to document that the negative effect of TELs in Oregon is not due to reduced expenditures. The state's school-finance equalization (SFE) tends to offset funding differentials, so TELs have no significant effect on funding, but even if TELs did affect funding, the negative effect of TELs on achievement is significant even if district expenditures are held constant. Instead, the negative effect of more restrictive TELs appears to work by disrupting local planning. We isolate this effect by distinguishing the more uncertain first year of each biennial budget from the second year. Our quasi-experimental design accounts for district and year fixed effects, as well as for district-specific variations in expenditures and student attributes. Results are robust to a placebo test to reveal spurious correlation and to several alternative specifications.

*Earlier version presented at the Oxford Symposium on the Financing of Education (sponsored by the Journal of Education Finance at Oxford Union, December 2014).
\end{abstract}




\section{Introduction}

Over the last several decades, a majority of states in the U.S. enacted tax/expenditure limits (TELs) that constrain funding for local governments and school districts, enacted schoolfinance equalization (SFE) systems that reduce the variation in funding across school districts, or both. Oregon is one of the states to enact both. ${ }^{1}$ We examine the effect of TELs on student achievement in the context of Oregon's state-level SFE. ${ }^{2}$

A number of studies, including Dye and McGuire (1997) (DM), Figlio (1997), and Downes and Figlio (1998) (DF), find a significant link between TELs and lower student achievement. The DF evidence for the effect of TELs provides the most relevant point of departure for our analysis. DF estimate the effect of TELs in the context of state-level SFEs and find a significant link between TELs and lower student achievement in mathematics. In addition, DF suggest that that the negative effect of TELs may be due in part to non-pecuniary factors, such as loss of local autonomy in acquiring and directing resources to meet local needs and priorities. We extend the DF analysis in two distinct ways. First, unlike DF, we are able to account for the extent to which TELs are actually binding. Second, we are able to account for pecuniary effects of TELs that work by reducing funding, as well as for non-pecuniary effects that work in other ways, apparently by disrupting local district planning.

We apply a quasi-experimental design to data for public school districts in Oregon from 2006 through 2011. The design accounts for: 1) factors important in each district but common to every year; 2) factors important in each year but common to every district; and 3) district-level

\footnotetext{
${ }^{1}$ The Advisory Commission on Intergovernmental Relations (1995) provides details of TELs.

${ }^{2}$ Origins of this paper are found in Davis and Vedder (forthcoming).
} 
variations over time in student and other district attributes. We isolate non-pecuniary effects of TELs by comparing estimates with and without pecuniary resources held constant and by exploiting the biennial budget cycle in Oregon, in which state-level SFE funding is known earlier and with greater certainty in the second year of the cycle than the first; we posit that in the first year, local tax revenues in districts with less restrictive TELs provide a buffer against the issues posed by the greater uncertainty of state-level SFE funding. The estimates indicate that more restrictive TELs have a significantly negative effect on the percentage of eighth-grade students who test at or above grade level in mathematics proficiency, whether or not district expenditures are held constant — there is a non-pecuniary mechanism at play. Indeed, more restrictive TELs have no significant effect on district expenditures, presumably due to the offsetting effects of SFE. The restrictiveness of TELs is predetermined each year, but not randomly assigned, so estimates are potentially subject to endogeneity or other biases. Hence, we employ the quasiexperimental design we've described and probe validity using alternative specifications and a placebo test aimed at uncovering the possibility of spurious correlation.

The negative effect on achievement is significant in the first year of the biennial cycle, and yet not significant in the second, more predictable, year. This result suggests that the negative effect in the first year is related to the greater uncertainty in funding present in the first year and possibly, to disruptions in planning: the negative effect of compression in the first year dissipates by the second year, just as one would expect if the first-year effect were due to the kind of transitory disruption in planning suggested by anecdotal evidence.

Our evidence confirms two key results from DF and points to a potentially problematic interaction between TELs and SFE that appears to work by disrupting district planning. We 
provide examples of specific cases and types of disrupted plans, including teacher recruitment and assignment, class sizes, curriculum, and scheduling.

The following section briefly summarizes the results of other, closely-related studies. Section 3 outlines the evolution and key aspects of TELs and SFE in Oregon. Section 4 explains the data and empirical specifications used to test our hypotheses. Section 5 presents the empirical results, including robustness checks and a placebo test of their validity. Section 6 discusses the limitations of our results.

\section{2. $\quad$ Related Studies}

We noted the most closely related studies of TELs (DM, DF, and Figlio, 1997). The number of other related studies is vast. For brevity, we highlight DM, DF, and a few other studies of particular relevance. Readers may wish to refer to DF for a more expansive review.

\subsection{Do Resources Matter?}

Much of the existing literature examining the link between school expenditures and student performance finds little or no significant effect. Prominent examples include Hanushek (1986, 1996) and Hoxby (2004). Balu (2011) focuses on issues related to the funding volatility important to results here; and BenDavid-Hadar and Ziderman (2011) focus on methods of distributing funds across districts and schools.

\subsection{Do TELs Matter?}

Evidence that TELs affect funding is more abundant than evidence that they affect achievement. DM, DF, Dye and others (2005), and McMillen and Singell (2007) are examples 
of studies that link TELs to reduced funding.

Dye and others (2005) find that while TELs reduce the growth of total school-district expenditures, the effects do not increase over time.

McMillen and Singell find a significant decrease in funding for states that adopted a tax limit between 1990 and 2000, but no increase in class size, a result they explain by suggesting that cuts are disproportionately small in instructional areas because instructional costs are relatively fixed in unionized districts.

In addition to finding a link between TELs and funding, DF find that imposition of TELs in a state reduces mean student performance in mathematics and that the reduction is greater for poorer district areas. DF use detailed data from the National Longitudinal Survey of the High School Class of 1972 and the 1992 National Educational Longitudinal Survey to control for demographics, and Census data to determine school district attributes and to compare achievement levels on reading and mathematics assessments in 1972 and 1992. They find a significant decrease in mathematics scores, but no significant effect on reading scores.

While other studies link TELs to lower expenditures and lower student performance, no study has estimated the link between revenue actually lost to TELs and student performance, as we do here.

\section{School Finance in Oregon}

This section summarizes key features of the complex system of TELs and SFE in Oregon. $^{3}$ We focus only on key details central to our analysis.

Oregon established property taxes in the mid-nineteenth century as a levy-based system

\footnotetext{
${ }^{3}$ Information for this section is drawn from the Oregon Department of Education at: (http://www.ode.state.or.us/search/results/?id=168).
} 
in which local entities set their own tax rates for schools and other local government functions and apply the rates to current assessed values of area properties (up to a rate of $\$ 15$ per $\$ 1,000$ of property value).

Prior to 1991, local property taxes provided almost all of the revenues for public school districts in Oregon. In that year, voters approved Measure 5, which limited property taxes for school operations to no more than $\$ 5$ per $\$ 1,000$ of a property's assessed value, and placed greater responsibility on the state for funding public schools. Hence, the state legislature enacted a system of school-finance equalization (SFE) that same year. In 1997, Measure 50 placed limits on assessed values. Each property's assessed value was rolled back to its 1995-96 value less 10 percent, and growth in value was limited to 3 percent per year. The cap on growth of assessed values has led to stark anomalies in the ratio of assessed to market values of various properties. (The appendix provides one example.) The limitations of Measures 5 and 50, together with the state's SFE, shifted the majority of school funding to the state, with roughly 70 percent of revenues now provided by the state. Additional local revenues, even if approved by voters, are limited in two ways: by the TELs and by the state's SFE. With respect to TELs, property tax revenue is compressed by caps on tax rates and by caps on growth in assessed values. Revenue not collected because of TELs is 'compressed' revenue, and 'tax compression' is the ratio of compressed revenue relative to the tax revenue that would be collected in the absence of the limits. Tax compression provides an explicit measure of the degree to which the TELs are binding for each school district. With respect to SFE, with few exceptions, the state's SFE funding formula tends to offset local tax revenues.

Oregon has a biennial budget cycle, and revenues and funding decisions are much more uncertain in the first year than in the second. School districts receive preliminary SFE funding 
estimates from the state by early summer of the first year, but these are revised numerous times through the legislative session and into the summer, often too late for timely hiring and assignments of teachers, or for setting class sizes and schedules. Instructional plans in districts with little or no buffer of local funding can be disrupted-even if expenditures eventually turn out to be higher than anticipated. As an example, one district transferred hundreds of teachers, many into classrooms in which they had little to no experience, only to transfer many of them back out again later in the year into jobs in which they did have experience (Owen, 2013).

\section{Data and Specifications}

\subsection{Data Sources}

Our data are taken from two primary sources: Oregon Department of Education reports on school-district budgets, demographics, and student assessments, and a report on tax compression rates compiled in 2013 by the League of Oregon Cities based on the Oregon Department of Revenue's reports on property tax levies and collections specific to each school district.

Data from these two sources yield a balanced set of complete panel data that span from the 2006-2007 academic year to the 2011-2012 academic year for 147 of the 192 school districts in Oregon, for a total of 882 observations. Data for tax compression are not available for 45 districts, so these districts are excluded.

\subsection{Mapping Years}

Tax compression for each academic year is predetermined, hence not subject to reverse causality. 


\subsection{Sample Period}

Our sample extends from 2007 to 2012 . A longer period that started prior to 1991 - the onset of Oregon's property tax reform-would be better, but comparable tax compression data are not available for earlier years. Another complication is that state standards for eighth grade mathematics assessment changed over earlier years, but did not change from 2007 to 2012 .

\subsection{Summary Statistics}

Table 1 presents summary statistics for variables used in our analysis. All percentages are expressed as percentage points. MATH, the dependent variable, is the percentage of students in each district who meet or exceed state standards for eighth grade proficiency in mathematics based on a standardized, statewide test. We focus on proficiency in eighth grade math primarily because the key result for achievement in DF is for eighth grade math, and secondarily because eighth grade math seems a good measure of a district's influence: in earlier grades and in reading, schools have relatively less influence on student performance than family background, and in later grades, assessment is complicated by more specialized and diverse curriculum, which can range from pre-algebra math to college-level calculus. We discuss empirical specifications and strategies in detail in the following section, but our set of independent variables includes: COMPRESSION, the ratio of tax revenues compressed by TELs relative to the total tax revenues that would be collected in the absence of TELs; EXPENDITURES, the total district operating expenditures in millions of dollars, regardless of source of funding; MINORITY, the percentage of students who are members of an ethnic minority; LUNCH, the percentage of students who qualify for a free or reduced lunch; and 
STUDENTS, the official count of the number of students, expressed in thousands.

\subsection{Baseline Specification}

Our primary hypothesis is that more restrictive TELs lower student achievement, all else the same. The baseline empirical specification used to test this hypothesis is expressed by Equation 1.

(1) $\quad$ MATH $_{i t}=c_{i}+c_{t}+$ a COMPRESSION $i t+B_{1} D_{i t}+B_{2} S_{i t}+e_{i t}$

$\left(\mathrm{MATH}_{\mathrm{it}}\right)$ is the percentage of students in district (i) in year (t) who meet or exceed eighth grade standards in mathematics based on a standardized, statewide test. $\left(\mathrm{c}_{\mathrm{i}}\right)$ is an intercept for factors specific to each district but common to all years. $\left(c_{t}\right)$ is an intercept for factors specific to each year but common to all districts. COMPRESSION is the ratio of district tax revenue suppressed by TELs, relative to the tax revenue that would otherwise be collected, with (a) as the corresponding coefficient. (D) is a vector of time-varying, district-specific variables, such as expenditures and enrollments, with $\left(\mathrm{B}_{1}\right)$ as the corresponding vector of coefficients. $(\mathrm{S})$ is a vector of time-varying attributes of students in the district, such as the percentages of minority students or students eligible for free or reduced lunch, with $\left(\mathrm{B}_{2}\right)$ as the corresponding vector of coefficients. (e) is the residual error.

\subsection{Alternative Specifications}

Estimates of Equation 1 yield an estimate of the district-level effect of tax compression, but do not, on their own, identify the mechanism for the effect. For example, a negative effect could arise either by reducing resources (a pecuniary effect) or by disrupting the use of resources in some way (a non-pecuniary effect). We isolate these effects in several complementary ways: 
1) by estimating the baseline equation with and without district expenditures; 2) by estimating whether tax compression affects district expenditures; and 3) by contrasting the baseline estimate for the first years of each biennium with the estimate based on the second years. If, as we suspect, less restrictive TELs provide districts with a pool of local funds that serve as a buffer against the uncertainties of state-level SFE funding during critical phases of district planning, this effect should be more important in the first than in the second years of each biennium, since funding for the first year is typically much less certain and timely than for the second. Estimates for the second years provide the opportunity for a placebo test, since a negative effect from disruptions due to funding uncertainty should not be present in the second years. The importance of stable, predictable revenues in district planning is emphasized, for example, by Balu (2011). We also use a variety of alternative specifications to gauge robustness.

\section{Results}

\subsection{Baseline Model}

Table 2 presents regression estimates of Equation 1 for the first years of each biennium. Again, the dependent variable is the percentage (in percentage points) of eighth grade students who test at or above grade level in mathematics. Our key independent variable of interest is COMPRESSION, but fixed year- and district-specific intercepts are included to account for district-specific factors common to each year and year-specific factors common to each district; a number of time-varying, district-specific variables are also included as controls (number of students in logs, percentage of minority students and percentage of students eligible for free or reduced lunch). Non-linear squared terms are also added, where significant at the ten-percent level or better. However, district expenditures are not included in this initial specification, so 
the coefficient for COMPRESSION in Table 2 reflects both the pecuniary and non-pecuniary effects of TELs. Standard errors are robust, corrected for both heteroscedasticity and the clustering of multiple districts in each year.

The overall power of the regression is high, with an R-squared value of 0.644 . The linear term for compression (1.67) is not significantly different from zero $(\mathrm{p}=0.217)$, but the squared term for compression $(-0.140)$ is significantly negative $(\mathrm{p}=0.053)$, indicating that the effects of an increase in compression are increasingly negative as compression rises. For example, the estimated decline in achievement due to compression is negligible for districts with low compression rates (well below 10 percent), but for districts with high compression rates (well over 10 percent), the estimated decline in achievement is as high as five percentage points. Unlike DF, we do not find significantly more negative effects for poorer districts.

Estimates for the other explanatory variables indicate a significant effect at traditional levels of significance only for MINORITYSQ (the percentage of minority students squared). In this case, the coefficient $(0.011)$ is statistically significant $(\mathrm{p}=0.022)$ but small.

\subsection{Distinguishing Pecuniary from Non-Pecuniary Effects}

To what extent is the negative effect of compression in Table 2 due to pecuniary effects working through reductions in expenditures? To address this question, Table 3 presents estimates of the baseline regression, but with district expenditures held constant by including them as an additional regressor. ${ }^{4}$ Estimated coefficients for COMPRESSION change only slightly, and the negative effect for COMPRESSIONSQ remains significant $(\mathrm{p}=0.040)$. Hence, we know that the significant negative effect is not due to pecuniary effects of changes in

\footnotetext{
${ }^{4}$ Results are equivalent if both operational and capital expenditures are included.
} 
expenditures. Indeed, as is often found, expenditures have no significant effect on achievement. Nevertheless, we pursue the possible pecuniary effects of compression in Table 4, which presents estimates of the baseline regression, but with expenditures as the dependent variable instead of grade-level achievement in math. Neither the coefficient for COMPRESSION nor COMPRESSIONSQ is significant at traditional significance levels $(\mathrm{p}=0.89$ and 0.72 , respectively), confirming the insignificance of tax compression effects that work through reduced expenditures.

\subsection{Understanding Non-Pecuniary Effects}

To better understand the nature of the negative (non-pecuniary) effect of tax compression, we rely on differences in the uncertainty of funding between the first and second years of the biennial cycle. If, as we hypothesize, the negative effect of compression is due to the greater uncertainty of funding in the first year of each biennium, one would expect to find no significant negative effect in the data for second years. Table 5 presents this placebo-effect

estimate based on data for the second year in each biennium. As expected, compression has no significant negative effect in the second-year data. We can also rely on comparisons between the first and second years to understand the extent to which the negative first-year effect is related to a transitory disruption in planning. While this type of transitory disruption in district planning could have effects that persist into the second year, one would expect the negative effects to diminish or disappear by the second year. Table 6 presents the relevant estimate, using first-year data for compression, but second-year data for all other variables, including math achievement. Consistent with interpreting the first-year negative effect as a transitory disruption in planning, the negative first-year effect of compression dissipates by the second 
year, as reflected in the smaller and insignificant coefficient for first-year compression squared

in Table 6. Indeed, the positive coefficient for the linear compression term is now significant ( $p$ $=0.074)$.

\section{Limitations}

Our analysis of the effects of TELS is subject to several limitations. First, we are not able to rely on a randomized experimental design to avoid potential issues of systematic bias. That being impossible in this case, we instead rely on a multi-pronged strategy: 1) a wellarticulated, quasi-experimental design that controls for the influence of factors that vary by district but not by year, factors that vary by year but not by district, and key factors that vary by both district and year; and 2) our baseline estimates are subjected to several robustness checks and a placebo test, in which we find no significant effect for tax compression in the second years of the biennial data. Another limitation is that we do not have the detailed data for district planning efforts to identify the direct effect of compression on disruptions to planning. Instead, we infer the mechanism indirectly in several ways: by finding no effect for tax compression in the second, less uncertain years; by finding that the first-year effect of tax compression dissipates by the following year; and by interpreting the results through the lens of substantial anecdotal evidence of disruptions to district planning.

\section{Conclusion}

Our estimates are novel in two respects. First, they are the first to link student achievement to the extent to which local tax and expenditure limits actually restrict district revenues. Second, they identify a significant non-pecuniary effect, which appears to work by 
disrupting district planning. In the context of a state-wide system of school finance equalization, local limits have no significant effect on district operating expenditures, but do appear to play a role in reducing the ability of districts to use local funds as a buffer against the uncertainty of state-level funding during years when that funding is less predictable. 


\section{References}

Balu, Rekha. 2011. "The Neglected Role of School District Revenue Instability: Measurement, Causes, and Responses,” Dissertation, Stanford U.

BenDavid-Hadar, Iris, and Adrian Ziderman. 2011. "A New Model for Equitable and Efficient

Resource Allocation to Schools: The Israeli Case." Education Economics 19:4, 341-362.

Davis, Matthew, and Andrea Vedder. Forthcoming. "The Real Consequences of Property Tax Compression for Oregon Public Schools.” Oregon Undergraduate Research Journal. U. Oregon.

Dye, Richard F., and Therese McGuire. 1997. "The Effect of Property Tax Limitation Measures on Local Government Fiscal Behavior." Journal of Public Economics.

Dye, Richard F., and others. 2005. "Are Property Tax Limitations More Binding Over Time?" National Tax Journal. 48:2, 215-225.

Figlio, David N. 1997. “Short-Term Effects of a 1990s-Era Tax Limit: Panel Evidence on Oregon's Measure 5." National Tax Journal.

Hanushek, Eric A. 1986. "The Economics of Schooling: Production and Efficiency in the Public Schools.” Journal of Economic Literature 24 (September): 1141-1177.

Hanushek, Eric A. 1996. “School Resources and Student Performance.” In Does Money Matter? The Effect of School Resources on Student Achievement and Adult Success, ed. Gary Burtless. Washington, D.C.: The Brookings Institution.

Hoxby, Caroline M. 1996. “All School Finance Equalizations Are Not Created Equal: Marginal Tax Rates Matter.” Cambridge, MA: Harvard University. March. Mimeo.

Owen, Wendy. 2013. "Beaverton School District in Review 2013.” Oregonian, Sept. 13, "Oregon Live." 
Advisory Commission on Intergovernmental Relations and Center for Urban and Environmental Policy at Indiana University. 1995. Tax and Expenditure Limits on Local Governments.

\begin{tabular}{|lrrrrr|}
\hline \multicolumn{6}{|c}{ Table 1. Summary Statistics for Variables - Both Years of Biennia } \\
Variable & Obs & \multicolumn{1}{c|}{ Mean } & Std. Err. & \multicolumn{1}{c|}{ Min } & \multicolumn{1}{c|}{ Max } \\
MATH $^{*}$ & 875 & 65.21 & 13.07 & 14.29 & 95.00 \\
COMPRESSION* & 875 & 2.02 & 2.28 & 0.00 & 16.83 \\
MINORITY* & 875 & 22.94 & 15.11 & 2.30 & 80.59 \\
STUDENTS** & 875 & 3.51 & 6.48 & 0.08 & 45.04 \\
LUNCH* & 875 & 52.17 & 15.08 & 2.47 & 91.70 \\
EXPENDITURES*** & 875 & 32.40 & 6.32 & 1.51 & 526.00 \\
\hline
\end{tabular}

*MATH, COMPRESSION, MINORITY, LUNCH in percentage points.

**Student count in thousands

$* * *$ Operating expenditures in millions

(see text for variable definitions and sources for data)

\begin{tabular}{|lccr|}
\hline \multicolumn{2}{|c|}{ Table 2. Baseline Math Regression for First Years } \\
& \multicolumn{3}{c|}{ Obs: 437} \\
Variable & Coef. & R-Sq: .644 \\
COMPRESSION & 1.67 & 1.35 & Prob \\
COMPRESSIONSQ & -0.14 & 0.07 & 0.217 \\
LNSTUDENTS & 10.94 & 11.57 & 0.053 \\
MINORITY & 0.04 & 0.38 & 0.345 \\
MINORITYSQ & 0.01 & 0.05 & 0.913 \\
LUNCH & 0.12 & 0.17 & 0.022 \\
\hline
\end{tabular}

${ }^{1}$ Robust standard errors

(year and district binaries included in regression, but omitted from table) 


\begin{tabular}{|lrrr|}
\hline \multicolumn{2}{|c|}{ Table 3. Baseline Math Regression for First Years Including Expenditures } \\
& & & $\begin{array}{r}\text { Obs: } 437 \\
\text { R-Sq: } 645\end{array}$ \\
Variable & Coef. & Std. Err. ${ }^{1}$ & Prob \\
COMPRESSION & 1.78 & 1.33 & 0.182 \\
COMPRESSIONSQ & -0.16 & 0.07 & 0.040 \\
LNSTUDENTS & 4.14 & 19.03 & 0.828 \\
MINORITY & 0.08 & 0.39 & 0.834 \\
MINORITYSQ & 0.01 & 0.05 & 0.022 \\
LUNCH & 0.11 & 0.16 & 0.504 \\
LNEXPENDITURES & 8.55 & 18.88 & 0.651 \\
\hline
\end{tabular}

${ }^{1}$ Robust standard errors

(year and district binaries included in regression, but omitted from table)

\begin{tabular}{|lrrr|}
\hline \multicolumn{3}{|c}{ Table 4. Expenditure Regression for First Years } & Obs: 441 \\
& & & R-sq: .999 \\
Variable & Coef. & Std. Err & \\
COMPRESSION & -0.04 & 0.24 & Prob \\
COMPRESSIONSQ & -0.01 & 0.01 & 0.89 \\
LNSTUDENTS & 7.26 & 1.68 & 0.72 \\
MINORITY & -0.15 & 0.08 & 0.00 \\
MINORITYSQ & 0.01 & 0.01 & 0.06 \\
LUNCH & -0.01 & 0.02 & 0.10 \\
\hline
\end{tabular}

${ }^{1}$ Robust standard errors

(year and district binaries included in regression, but omitted from table) 


\begin{tabular}{|lrrr|}
\hline \multicolumn{3}{|c|}{ Table 5. Baseline Math Regression for Second Years } \\
& & & Obs: 438 \\
& & & R-sq: .683 \\
Variable & Coef. & Std. Err. ${ }^{1}$ & Prob \\
COMPRESSION & 1.37 & 0.94 & 0.147 \\
COMPRESSIONSQ & -0.05 & 0.05 & 0.375 \\
LOGSTUDENTS & -2.35 & 10.07 & 0.816 \\
MINORITY & 0.01 & 0.37 & 0.992 \\
MINORITYSQ & 0.01 & 0.01 & 0.302 \\
LUNCH & -0.22 & 0.13 & 0.110 \\
\hline
\end{tabular}

${ }^{1}$ Robust standard errors

(year and district binaries included in regression, but omitted from table)

\begin{tabular}{|c|c|c|c|}
\hline \multicolumn{4}{|c|}{ Table 6. First-Year Compression w/ Second-Year Data } \\
\hline & & & Obs: 439 \\
\hline & & & R-sq: .686 \\
\hline Variable & Coef. & Std. Err. ${ }^{1}$ & Prob \\
\hline COMPRESSION & 2.15 & 1.20 & 0.074 \\
\hline COMPRESSIONSQ & -0.11 & 0.07 & 0.124 \\
\hline LNSTUDENTS & -2.92 & 10.08 & 0.772 \\
\hline MINORITY & 0.01 & 0.38 & 0.994 \\
\hline MINORITYSQ & 0.01 & 0.01 & 0.298 \\
\hline LUNCH & -0.21 & 0.13 & 0.128 \\
\hline
\end{tabular}

${ }^{1}$ Robust standard errors

(year and district binaries included in regression, but omitted from table) 


\section{Appendix}

The home in Portland, Oregon, pictured below-a refurbished, 4-bedroom, 3-bathroom Victorian home on a corner lot, just eight blocks from a popular Whole Foods grocery storesold on April 1 of 2014 for \$490,000. But in 1996, it was dilapidated, in the middle of a highcrime neighborhood, and assessed at a value of just $\$ 14,030$. The new owner will pay a total of just $\$ 339$ in property taxes in 2014 , for an effective tax rate of only $0.069 \%$. The total tax due on the purchase price of $\$ 490,000$ would be $\$ 7,350$ - more than 20 times higher.

\section{An illustration: 4239 NE 7th Ave.}

4 beds, 3 baths, $2,280 \mathrm{sq}$. ft. Desirable corner lot in PDX

Asking price: $\$ 499,900$

Sale price, April 1: $\$ 490,000$

Assessed Value (2013): \$14,030

Real Market Value: $\$ 114,000$

Property tax: $\$ 339$ Effective rate: $0.069 \%$

Data and image source: Trulia.com

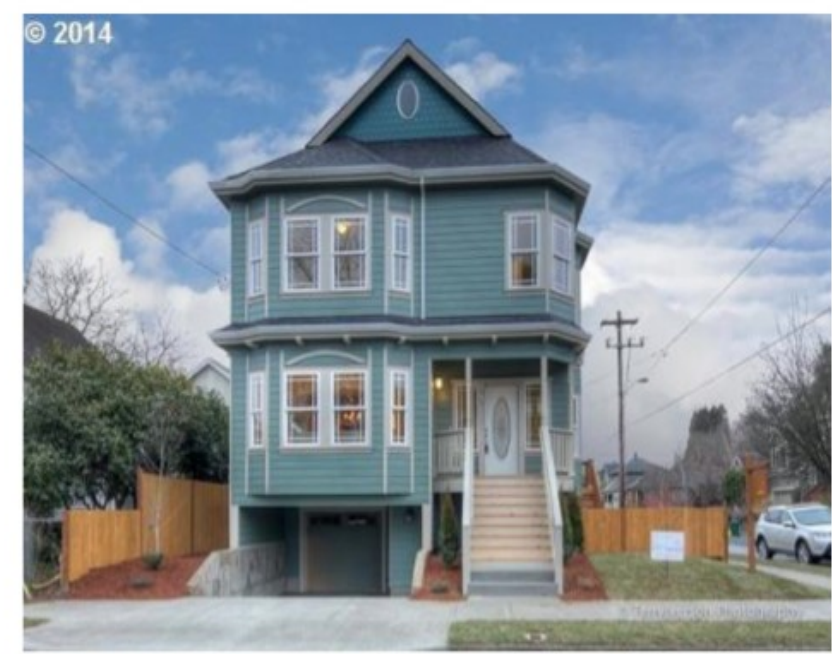

